\title{
Research on the Application of Fiscal Big Data against the Background of Internet Plus
}

\author{
Fengrui Liu, Xiaohui Hu, Fuchang Li* \\ Yunnan Normal University; School of Economics and Management \\ *Corresponding author
}

\begin{abstract}
With the introduction of the "Internet Plus" and wide application of big data, the demand for the technology by the fiscal sector is increasing. The 19th session of National Congress of the Communist Party of China put forward the theory of socialism with Chinese characteristics in the new era of Xi Jinping. At the same time, under the guidance of Xi Jinping's new era theory, China has begun to build an "Internet plus financial big data" system and constantly explores development methods. This paper analyzes the process of China's fiscal informatization construction through the Stages of Growth Model, which includes six stages: initiation, contagion, control, integration, data administration and maturity. It shows that China is in the stage of data administration and is developing mature. Through studying the opportunities and problems encountered in the development of China's fiscal big data application, this paper gives a reflection on the application of fiscal data in the context of the Internet + background and puts forward suggestions for the development of big data technology.
\end{abstract} Model

Keywords-Internet Plus; Fiscal Big Data; Stages of Growth

\section{INTRODUCTION}

Since entering the 21 st century, especially after the 18th session of national congress of the communist party of China, China's Internet technology has been increasingly developed. The speed of broadband and mobile network has rapidly increased within a few years, and network technology has also developed rapidly. Today, the ability of information management has been an essential capability in all industries. Xi Jinping New Era Socialism with Chinese Characteristics asks coordinated advancement of the "four comprehensive" strategic layout. There is a large gap between financial departments in different regions. In view of the unbalanced and uncoordinated problems in the development of our country, efforts have been made to improve the information processing and data analysis capabilities, and this capability is particularly important for the financial sector. The provision of public goods and public services by the state in order to meet the public needs of the society is fiscal, and financial supervision provides legal guarantees for the financial revenue and expenditure of financial departments and the development of fiscal activities, and is also an important part of the operation of the national machinery.

Nowadays, as the world enters the age of the Internet, the management of information becomes even more important. Under this background, Prime Minister Li Keqiang proposed the "Internet Plus" plan which made a new orientation on the development of the fiscal sector. Xi Jinping New Era Socialism with Chinese Characteristics has further demanded the acceleration of the establishment of a modern financial system and scientific financial supervision. The "Internet Plus" action plan is closely linked with the application of "big data", and big data can be widely applied is relied on the development of the Internet. "Internet plus fiscal big data" is an effective combination of the Internet and the real economy, which can promote the development of the financial sector, allow the financial sector to provide better services to the society, and implement the government's idea of insisting on economic construction as the center. In the current context of "Internet plus fiscal big data," the financial sector's strategy for providing public goods and services can be optimized and improved based on the analysis results of big data. Financial supervision can also be more efficient through the advanced technologies and information management of the Internet plus era, and make contributions to the financial sector and supervision departments, let them meet the needs of the times better.

\section{THE CHARACTERISTICS AND SIGNIFICANCE OF BIG DATA APPLIED TO FISCAL}

\section{A. The characteristics of big data applied to fiscal}

Big data usually has five characteristics, these five characteristics can be summarized as five "V"s: Volume, Velocity, Variety, Value, Veracity. Volume refers to the amount of data, and the size of the data can reach the PB level, while the total capacity of a hard disk of home computers is mostly between $1 \mathrm{~TB}$ and $6 \mathrm{~TB}(1 \mathrm{~PB}=1024 \mathrm{~TB})$.Velocity refers to the speed of data processing. With the help of cloud computing and supercomputers, it is possible to complete complex programs in a short time, analyze multiple variables at the same time, and finally analyze the precise conclusions of the problem. Variety refers to a variety of data types, such as video, audio, text, pictures, and computer language data, which are stored together and analyzed at the same time. Value refers to the lower value density of data due to the large volume of data. In the case of the Chinese public security system searching for clues through the Skynet system, for example, the public security department needs to analyze the large amount of video and picture materials recorded by the Skynet system. The valuable clues may be only a few seconds in hundreds of hours of video. There may also be only a few valuable clues in 
thousands of photos. Veracity refers to all the data used by big data analysis data, rather than using sampled data. The conclusion obtained through the analysis of all data is closer to the reality than using sampled data.

When applying big data to fiscal, the above features are not all applicable. Fiscal big data has its own unique features in relation to big data in other industries. First, the structure of financial big data is simple. Most of fiscal big data are textbased data, occupying a small space, easy to save and read. When processing data, the finance department only needs to process simple structured data to get what they want. Second, fiscal data has a high value. Most financial big data directly correspond to the corresponding policy implementation and the provision of public services. The results of data processing can usually directly reflect the effects of financial sector implementation policies. Last but not least, fiscal big data has a strong linkage. Behind the fiscal big data, it is often linked with the government's management activity data and socioeconomic activity data. This kind of connection can make fiscal big data more reflective of the social reality in the context of the Internet plus. And the analysis results obtained can better provide fiscal departments with guidance on public goods and services.

\section{B. The significance of developing fiscal big data}

In the new era of rapid technological development, exploring and advancing the innovation of the financial system and the practical innovation of financial supervision are challenging. Relying on traditional financial development methods can no longer meet the financial needs of the new era, and it is necessary to introduce new, high-tech "productivity" to improve the financial development process. Big data and the Internet are the productivity of the current Internet age. Productivity is the most active factor in social production and a decisive force in the development of social history. Changing the productivity in fiscal is an inevitable requirement for advancing the rapid development of fiscal services. The application of Internet plus fiscal big data in the new era is to introduce the latest productivity into the financial sector, promote the key role of the financial sector to better play its role, improve and develop the socialist fiscal system with Chinese characteristics, and promote the modernization of the fiscal system. The revenue and expenditure of fiscal funds involves all government departments, public institutions, stateowned and private enterprises, various social groups and individuals. Therefore, the fiscal big data should include the operating status of government, public institutions, state-owned enterprises, and most private enterprises, and be able to link as much as possible to the national economy and people's livelihood, make the data as broad as possible, and reflect the national behavior or personal behavior behind the use of funds, providing guidance for better use of financial resources. At the same time, these data can also be interconnected between government departments to provide data resources for other government departments. In the provision of public services by the fiscal sector, fiscal big data can make the public services provided by the government more efficient and more satisfying to the needs of the public. The application of financial big data is also conducive to the transformation of the financial sector's working methods, processing what is impossible for people to carry out or extremely difficult to carry out which liberating productivity, people's work tends to analyze the results of big data processing.

\section{FISCAL INFORMATIZATION AND DEVELOPMENT IN}

CHINA: ANALYSIS BASED ON STAGES OF GROWTH MODEL

"Internet plus" and "big data" are both new references proposed in recent years, but the development of computer applications and information processing began long in China. This paler analyzes the development of fiscal informatization in China based on the stages of growth model proposed by Harvard University professor Richard Nolan. The model attempts to help managers explain the needs and applications of information technology in the development process of enterprises or government agencies.

After decades of development, the stages of growth model is now divided into six phases. The first phase is the initial phase, which corresponds to China's fiscal development phase before the reform and opening up, that is, before the 1980s.In this stage, few departments introduced computer technology. Only a few areas of the fiscal sector began to use computers to process data. The information between fiscal departments in various regions was difficult to interconnect, and information processing was almost entirely handled by humans. Processing efficiency was low that time.

The second phase is the contagion phase, during which the application of information technology begins to spread and more departments begin to use computers to process information. Corresponding to China's fiscal development stage is the initial period of reform and opening up, that is, the late 1970s and early 1980s.In 1979, the Ministry of Finance introduced the computer system of Japan to set up the computer center of the Ministry of Finance. This is the start of the informatization construction of China's fiscal department. During this period, fiscal management and supervision just introduced computer technology, and various departments within the fiscal sector are still weak in the ability to use computer technology to process information.

The third phase is the control phase, the demand for data processing in this phase has increased. Various departments have begun to pay attention to the use of computer technology for data processing. Corresponding to China's fiscal development stage is the middle and late 1980s, that is, after 1985.During this period, the Ministry of Finance has plans to organize the construction of the financial sector information system nationwide. We have established a national fiscal and taxation information system that includes finance, state-owned assets, and taxes covering the four levels of central, provincial, prefecture-level cities and counties. The information system continued to develop between the seventh five-year plan and the ninth five-year plan until it became more perfect. The construction of informationization of the fiscal department was effectively regulated and developed in this period. The application of computers no longer stays in simple print and single-office information processing, but begins to interact via the Internet. However, due to lack of experience and corresponding regulations, the phenomenon of blindly 
expanding hardware purchases and impractical software development has hindered the development of fiscal informatization.

The forth phase is the integration phase, at this phase, various departments have changed from managing single or series of computer information processing organizations to managing information resources as a integration, which is a great progress. Corresponding to China's financial information development stage for the early 21 st century. In 2002, the Ministry of Finance named the "Government Financial Management Information System" previously planned and established as the "Golden Finance Project" or "GFMIS" and plans to realize the full functions of the system in 2008.There are two parts in GFMIS. The first is the fiscal business application system, including the budget management, the centralized revenue of the treasury, the centralized management of treasury bonds and other core fiscal business management and macroeconomic analysis and forecasting system. The second is an information integration network system that covers all levels of fiscal management departments and departments who use fiscal capital in China. The system is supported by a large-scale information network, which has formed the embryonic form of Internet plus fiscal data and is a revolutionary change in fiscal management. At this phase, China's fiscal information development has entered a period of rapid development, and the processing and interaction of information has developed rapidly and efficiently. Resource sharing starts among different fiscal departments. Different data is integrated into a database system. The unified computer server system, data processing technology and data processing standards provide effective protection for data interconnection.

The fifth phase is the data administration phase, information processing at this phase began to become more and more complicated. Instead of analyzing a single data type, it analyzes the data of many different carriers, such as video, audio, and text data. The corresponding period for the completion of the construction of GFMIS in 2008.China's fiscal informationization construction is at this stage. Internet plus finance data has begun to be used in fiscal activities. The nationwide unified fiscal network support system was also successfully established. The information between the departments involved in the fiscal activities was networked. The information was transmitted to the cloud server in real time, and the information between the departments was interconnected. The integration of financial information is still being carried out in an orderly manner. The role of computer information systems in data processing has begun to be truly effective. Financial management and information processing have begun to integrate organically.

The sixth phase is the maturity phase, in this phase, all departments have fully realized the interconnection of data, and the application of Internet plus fiscal data provides perfect data analysis and policy guidance for fiscal activities. China's financial informatization construction has not yet entered this phase, efforts are still being made to establish an information interconnection mechanism between fiscal departments at different levels in various regions so as to effectively provide corresponding public services. The model summarizes the experience and laws of developed countries in the process of information system development, and it can also adapt to the development of the informatization of China's fiscal sector. The informationization process of China's fiscal department is fast, and there are still more or less problems. This requires the coordination of relations between various departments and the development of fiscal big data in the context of Internet plus.

\section{OPPORTUNITIES AND PROBLEMS IN FISCAL BIG DATA CONSTRUCTION UNDER THE BACKGROUND OF INTERNET PLUS AND SOCIALISM WITH CHINESE CHARACTERISTICS IN THE NEW ERA OF XI JINPING}

Since the second decade of the 21 st century, a new round of information technology revolution based on big data has swept the world. The developed economies such as the United States, the European Union and Japan are all vigorously supporting the development and investment in scientific research of big data, developing and applying research results based on big data. According to the analysis of stages of growth model above, at present, China is in the phase of data management and attaches great importance to the rapid development of big data technology. Under the guidance of the theory of the new era, it has formulated a series of measures to develop and apply big data, and actively respond to the Internet plus and big data era. Internet plus big data is providing convenience for our lives, providing many opportunities as well as many problems. In the era of big data, our private information is more likely to be leaked, and individual consumption habits can also be analyzed through big data. If it is used by companies or illegal organizations with ulterior motives, it will cause unpredictable losses. Similarly, the behavior of the financial sector may also be obtained through the analysis of big data. If the financial data are used illegally, it will cause huge losses in the society. Therefore, the development of big data is also a challenge for the fiscal sector.

\section{A. Opportunities for fiscal big data development}

It will help improve the efficiency of fiscal policy implementation. The formulation of fiscal policy often needs to consider the fiscal data of a large number of sectors in the society. In the new era, the application of big data can analyze more extensive and in-depth fiscal data. The amount of data referenced in the formulation of fiscal policy is not the same as before. More rigorous data analysis can lead to more consistent and practical conclusions. Big data analysis can not only analyze more fiscal data, but also analyze a large amount of business data in the social sector. These data are widely distributed in China's financial, taxation, banking, treasury and other business sectors, involving the treasury income and expenditure, social security systems and tax systems and other fields. Faced with such a huge amount of fiscal data and other relevant data, the original artificial fiscal analysis has been difficult to meet the requirements of the huge amount of information in the new era, and the information dissemination in the new era is faster, and the effective formulation of fiscal policies is even more important. This conforms to the concept of Xi Jinping New Era Socialism with Chinese Characteristics and focuses on economic construction. The application of Internet plus fiscal big data can provide better guidance and 
advice for the designation of fiscal policy and facilitate the formulation of more effective fiscal policies.

It will help promote the sharing of resources in the fiscal sector. Before the construction of the Internet plus fiscal big data, the data of most fiscal departments in China was decentralized, the construction of the interconnection mechanism was not perfect, the effective utilization rate of the data was low, and the financial informationization construction was unbalanced and uncoordinated. Because the data is scattered under various departments of finance, and it is difficult to effectively interconnect and interoperate, the efficiency of resource sharing among financial departments is low, and the formulation of fiscal policies and the implementation of fiscal policies have been affected. The financial sector's provision of public goods and services also lacks efficiency due to low data utilization rates. With the gradual development of Internet plus fiscal data and theoretical support from Xi Jinping New Era Socialism with Chinese
Characteristics, the data interconnection between fiscal departments has progressed rapidly, which has greatly increased the speed of information construction in the fiscal sector, and the efficiency of information transmission and utilization has greatly improved. The comprehensiveness and reliability of financial data have also been greatly enhanced, and the efficiency of financial activities has increased.

The fiscal expenditure has increased year by year, and the funds that can be put into the development of fiscal big data are more abundant. According to the data of fiscal revenues and expenditures released by the National Bureau of Statistics of China, it can be seen that the growth rate of China's fiscal expenditure is greater than the increase of fiscal revenue, which is conducive to the further construction of financial infrastructure, the development of fiscal big data technology, and the provision of big data to better serve financial activities. The following figure shows the changes in China's fiscal expenditure and income histograms:

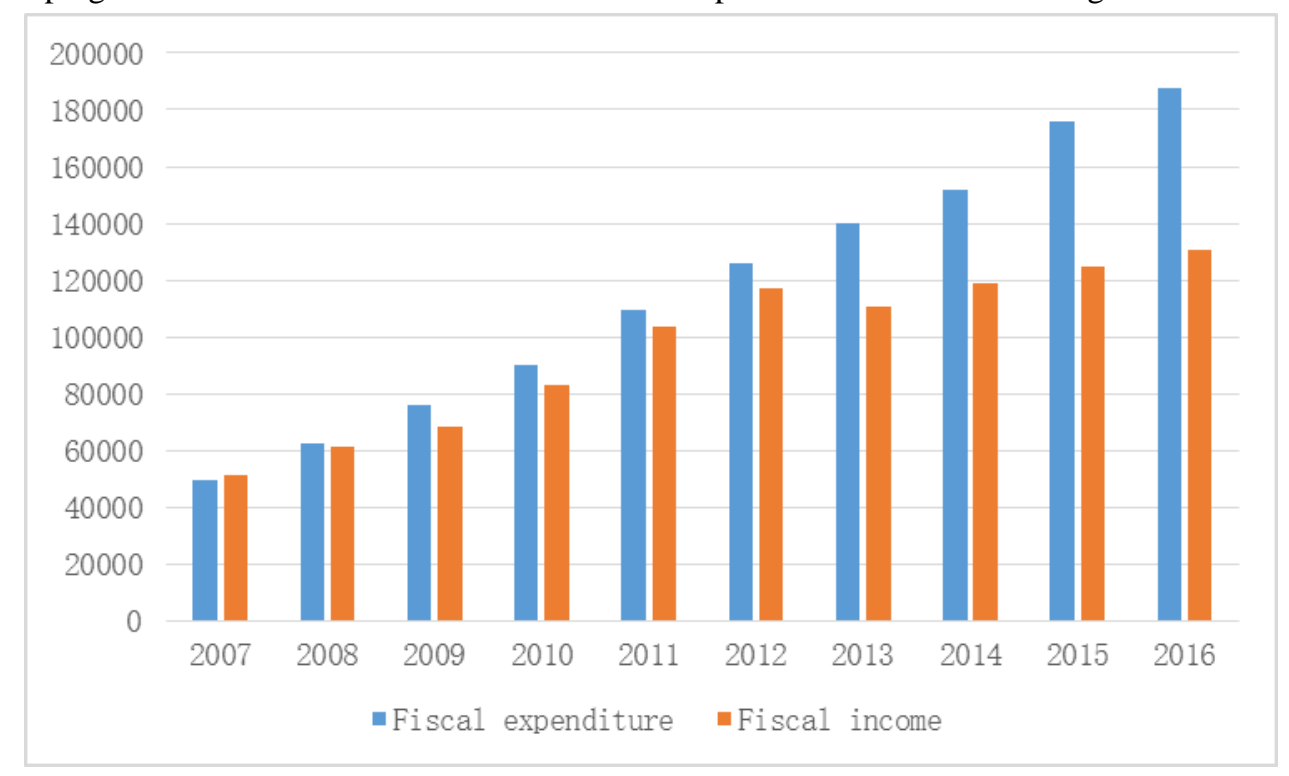

Fig. 1. China's fiscal revenue and expenditure (hundred million RMB)

\section{B. Problems of fiscal big data development.}

The financial data sharing mechanism is not mature. With the steady development of Internet plus fiscal big data, the data interconnection mechanism among financial departments is gradually improving. According to the analysis of stages of growth model above, China's current fiscal informatization construction is in the stage of data management and needs further development. It will eventually enter a mature stage and make financial services more efficient. Many provinces have actively established and improved the fiscal big data platform, but the level of fiscal big data construction varies among provinces and regions, and data interconnection still has certain resistance. Because of the different sources of data, the data processing models in each province may also differ due to differences in technology or types, which has led to resistance to financial data in horizontal transmission.
The classification and processing capacity of fiscal big data is not strong. There are many types of fiscal big data, and the amount of data is huge. However, in most regions, financial big data systems do not have powerful information classification processing capabilities and can't mature financial data. In the use of fiscal big data, it often happens that people need to manually extract data from the database and make reports. This is because the data in the current financial big data system is not sufficiently detailed and cannot be extracted from fiscal big data by software according to demand.

The construction of software and hardware facilities needs to be strengthened. Internet plus big data is based on highly efficient computer server systems, big data processing software, high-computation computers, and cloud storage devices. However, the current use of software is relatively inefficient. Different regions have different software development plans for the construction of big data in the fiscal department, which leads to different developments. Some software features are duplicative or inefficient. At the same time, the construction 
efficiency of hardware facilities in different regions is also different, and regions with insufficient funds may lack highperformance big data storage and processing equipment, resulting in different levels of big data processing capabilities between different regions.

Information security problems. In the age of Internet plus fiscal big data, the volume of big data will grow rapidly and it will also face information security problems. The data content of fiscal big data is closely related to the formulation of fiscal policies. If the data cannot be guaranteed, it will cause great negative effects or cause panic.

Fiscal expenditures have not invested enough in science, technology and education. Through the analysis of China's National Bureau of Statistics published data on China's fiscal expenditure from 2007 to 2016, we can see: China's expenditure on education and science and technology accounts for a relatively low proportion of total expenditures, with an average of 0.185 . The specific trends are shown in the figure below.

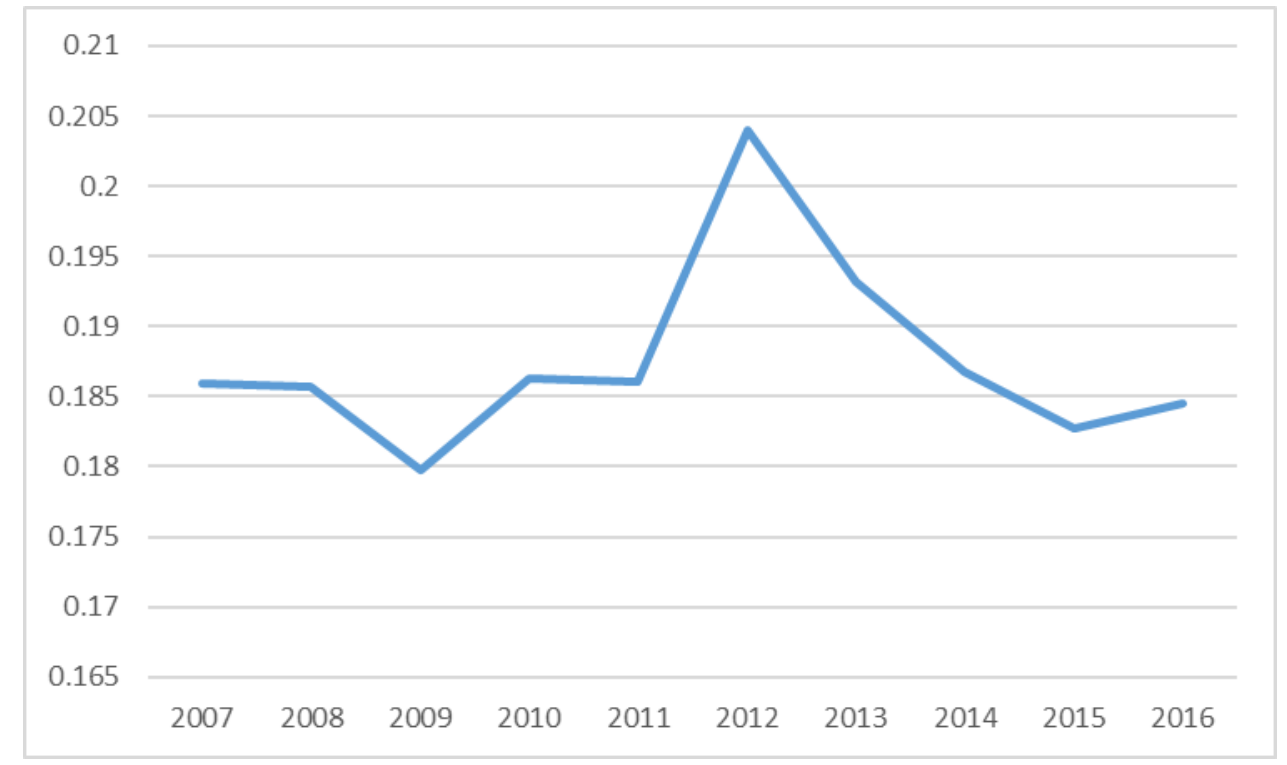

Fig. 2. Proportion of Education and Science and Technology Expenditure in China's Fiscal Expenditure

\section{SUMMARY AND SUGGESTION OF INTERNET PLUS FISCAL BIG DATA APPLICATION.}

In the physical reform of China's financial sector, technical support is an important content. In the context of the new era, the application of the Internet plus fiscal big data is a revolutionary technological innovation and a revolutionary development of productivity. Grasping this opportunity can advance the revolutionary progress of the system. The emergence and widespread use of the Internet has enabled the fiscal sector to expand its scope of management to an unprecedented degree. The fiscal sector's policies can properly involve all industries and even individuals, making the government's management capabilities and services people's capabilities have been effectively enhanced. Face with various problems in the era of Internet plus big data, the government must also face problems, solve problems, and analyze specific issues in an effort to seek better fiscal services. In order to better serve the society with Internet + fiscal data, this article uses the socialist theory of Chinese characteristics in the new era of $\mathrm{Xi}$ Jinping as the guide, and proposes the following suggestions:

Accelerate the mechanism of data interconnection and intercommunication among financial departments at all levels and build a cloud-based financial big data platform. The data platform is an important carrier for the construction of fiscal big data. The interconnection and interoperability of data contributes to the reference policies of other departments with reference to other departments. The degree of interconnection of information determines the degree of application of financial big data, and the financial sector needs to pay enough attention to it. At present, there are problems of unbalanced and uncoordinated development in China's financial informatization. To this end, it is necessary to coordinate and promote the "four comprehensive" strategic layout and accelerate the interconnection and interflow mechanism among fiscal departments.

Implement the "Internet plus fiscal big data" supervision. Through the comprehensive promotion of the application of "Internet plus fiscal big data", the supervision department supervises the financial affairs through the analysis of financial department data and data of other related departments. Using computer platforms with big data cloud computing capabilities to automatically detect relevant data, and manually monitor relevant indicators. Through the continuous improvement of fiscal supervision based on big data, a standardized and unified supervision model has been formed, and the effective supervision of the implementation of fiscal policies and financial services will continue in the context of the Internet in the new era.

Promote the construction of software and hardware facilities. The powerful cloud computing capability and server computers that can read and write data at high speeds are the 
basis of big data technology. Software with efficient management of information and data capabilities is a prerequisite for big data technology. Promoting the application of software and hardware for big data technology is an inevitable requirement for advancing the application of "Internet plus fiscal big data".

Broaden the extension of fiscal big data. Fiscal big data can not only focus on issues such as fiscal budget and fiscal implementation, but also pay attention to multidimensional information such as taxation, economy and society, and form coordinated and sustainable development among multiple departments.

Timely update and protect fiscal big data. It is particularly important to update the contents of financial big data in a timely manner. At the same time, data security is also an important part of fiscal big data construction. Data management departments under the finance department should adopt advanced scientific and technological protection systems to prevent lawbreakers and hackers with ulterior motives from using financial information to endanger society. The financial supervision system is also inseparable from the security of fiscal data. The protection of fiscal data can effectively increase the trust of enterprises and institutions in the fiscal sector and provide the basis for fiscal supervision and management.

Increase the proportion of education and science and technology expenditures in total fiscal expenditure and promote the development of science and technology. At the same time as the development of science and technology, fiscal big data technology will also benefit, improve the efficiency and capability of financial services, and make China's economic development more dynamic.

\section{ACKNOWLEDGEMENT}

The authors greatly appreciate the anonymous referees and the associate editor for their very valuable and helpful suggestions on an earlier version of the paper. This research is supported by the NSF of China (Grant No. 71562036, 71362028, 71262031), Project on Applied Basic Research in Yunnan province (2015FB142), Youth Leaders Project in Academic and Technical of Yunnan Province (2014HB009), and Yunnan provincial doctoral discipline construction planning (Applied Economics).

\section{REFERENCES}

[1] Tan Chen. Mengzhu Yang.Transmutation of State Governing Power Driven by "Internet Plus" and "Big Data Multiply"[J].Journal of Xinjiang Normal University(Philosophy and Social Sciences).Vol.37 No.5.Sep.2016.105-111.

[2] Wenhua Pei. Weiyi Cheng.A Study on Public Finance Audit Data Analysis in Big Data Environment[J].Audit Research.2017.3.53-58.

[3] Yuchi Shen.Reflections on China's Financial Information Sharing in the Era of Big Data [J]. Local Finance Research.2015.11.47-67.

[4] Xiaochen Lu.Zhen Qu.The Application of "Internet Plus Big Data Algorithm" in Taxation Work[J]. Tax Collection and Management.2017.2.108-110.

[5] Ruixiang Bi.Research on Big Financial System Construction Based on Big Data [J]. Local Finance Research.2017.12.15-20.

[6] Guiqing Xiao. The Great Significance of Xi Jinping Thought on Socialism with Chinese Characteristics for a New Era [J]. Journal of the Party School of the Central Committee of the C.P.C.2017.12.40-45.

[7] Chuanping Zhang.On Methodological Principles for Correctly Understanding Xi Jinping's Thought on Socialism with Chinese Characteristics for a New Era[J]. Nanjing Social Sciences.2017.12.1-14. 